\title{
The effect of protonation on the excited state dynamics of pyrimidine chromophores
}

Fotis Kournoutas, ${ }^{1}$ Ioannis Konstantinos Kalis, ${ }^{1}$ Michaela Fecková, ${ }^{2,3}$ Sylvain Achelle, ${ }^{2}$ Mihalis Fakis ${ }^{1, *}$

\author{
${ }^{1}$ Department of Physics, University of Patras, 26504, Greece. e-mail: fakis@ upatras.gr \\ ${ }^{2}$ Univ. Rennes, CNRS, Institut des Sciences Chimiques de Rennes - UMR 6226, 35000 Rennes, \\ France \\ ${ }^{3}$ Institute of Organic Chemistry and Technology, Faculty of Chemical Technology, University of \\ Pardubice, Studenská 573, Pardubice 53210, Czech Republic
}

\section{Highlights}

- The protonation effect on the excited state dynamics is investigated

- Two pyrimidine chromophores, bearing the $\mathrm{A}-(\pi-\mathrm{D})_{2}$ and $\mathrm{A}-(\pi-\mathrm{D})_{3}$ structure, are used

- Time resolved fluorescence spectroscopy (fs and ns) is employed

- Protonation using three different acids, CSA, TFA and AcOH is studied

- The dynamics of the neutral chromophores become faster upon protonation with $\mathrm{AcOH}$

\begin{abstract}
The effect of protonation on the photophysics and especially on the excited state dynamics of two pyrimidine chromophores, bearing the A- $(\pi-\mathrm{D})_{2}$ and $\mathrm{A}-(\pi-\mathrm{D})_{3}$ structure, is studied by means of fsps and ns time resolved fluorescence spectroscopy. Three different acids, namely camphorsulphonic (CSA), acetic (AcOH) and trifluoroacetic acid (TFA) were used. The chromophores bear the pyrimidine electron deficient heterocycle as electron-withdrawing group, used as protonation site, as well as diphenylamino electron donors. Protonation is revealed through the emergence of red-shifted absorption and fluorescence bands accompanied by a
\end{abstract}


quenching of the fluorescence of the neutral molecules. Time-resolved dynamics reveal that protonation with CSA and TFA do not influence the excited state lifetime of the chromophores pointing to a static quenching process. On the other hand, the lifetime is decreased upon protonation with $\mathrm{AcOH}$. Further investigation based on the Stern-Volmer plots showed that addition of $\mathrm{AcOH}$ leads to both dynamic and static quenching.

Keywords: Pyrimidine chromophores, protonation, dynamics, fluorescence spectroscopy.

\section{Introduction}

Organic fluorophores are important materials not only for their highly efficient fluorescence in the visible part of the spectrum, for use in lighting and imaging, but also because their fluorescence properties are highly dependent on the environmental conditions providing us with a sensitive and nondestructive way of sensing. The development of organic chromophores with suitable functional groups, capable of reacting physically or chemically with their environment and reporting these reactions through their fluorescence properties, via a remote access, is of tremendous scientific and technological interest. External impulses such as a change in polarity, ${ }^{1-4}$ viscosity, ${ }^{5-8} \mathrm{pH},{ }^{9-14}$ or the presence of metal ions ${ }^{15-22}$ can be transduced through fluorescence and become perceptible by naked eye.

More specifically, organic chromophores with nitrogen containing heterocycles such as pyridines, ${ }^{23-28}$ pyridazines, ${ }^{23,29,30}$ pyrimidines $^{23,31-34}$ and pyrazines ${ }^{23,35-37}$ are susceptible to protonation, resulting in new species with bathochromically shifted spectra. These heterocycles constitute electron accepting groups in D- $\pi$-A structures which result in efficient Intramolecular Charge Transfer (ICT) and are potential candidates for application in optoelectronics, sensors and non-linear optics. ${ }^{38-49}$ Protonation strengthens their electron accepting ability, enhancing the ICT. In some cases, protonation is also used in order to prepare white light emitting materials to be 
used in lighting and displays by simultaneously utilizing the fluorescence of the neutral and protonated species. ${ }^{23,50-57}$ It has been reported that energy transfer from the higher energy neutral to the lower energy protonated species takes place..$^{50,52,55}$ Partial energy transfer, where the fluorescence of the neutral species is not totally quenched and both species emit light, can result in white light emission. ${ }^{50}$ This method is of great importance, since white light is achieved by a single emitter existing simultaneously in two forms with supplementary emitting colors, while emission tunability can be simply achieved by altering the protonation conditions by employing different amounts of acid. Typically, in various other methods, white light emission is achieved by incorporating different chromophores, either chemically linked or self-assembled, having supplementary colors. ${ }^{58-61}$ Notably, the biggest challenge towards this goal, is the careful choice of chromophores paying attention on their energetics as well as their mixing conditions. By means of protonation, the laborious procedures for mixing of several chromophores with different fluorescent colors to produce white light is not required.

However, although white light emission upon protonation from chromophores containing azaheterocycles has been achieved and white organic light emitting diodes (WOLEDs) have been obtained using this strategy, the fundamental photophysical properties of these systems have been mainly studied by steady state spectroscopy while less attention has been given in their excited state dynamics. ${ }^{62}$ Such a study is crucial towards understanding the nature of the interactions among the neutral and protonated species as well as among the solute and different acids.

Very recently, our groups has studied the effect of protonation with acetic acid on the optical properties of pyridine-based chromophores, revealing a quenching of the neutral species fluorescence which was accompanied by a decrease of their excited state lifetime. ${ }^{62}$ In this work, the effect of protonation on the photophysical properties of two pyrimidine-based chromophores is addressed focusing on the excited state dynamics. For this reason time resolved fluorescence spectroscopy in the fs-ps and ps-ns timescales has been employed. The chromophores adopt the $\mathrm{A}-(\pi-\mathrm{D})_{2}$ and $\mathrm{A}-(\pi-\mathrm{D})_{3}$ topology where the diphenylamino fragment is used as electron donating group. The effect of protonation has been studied by using three acids namely camphorsulphonic 
(CSA), trifluoroacetic (TFA) and acetic acid ( $\mathrm{AcOH})$ revealing different effects in the excited state dynamics of the chromophores.

\section{Experimental}

\subsection{Materials}

The chromophores under study are shown in figure 1 . They bear pyrimidine electron accepting group and diphenylamino electron donors. $\mathbf{C 2}$ adopts a pseudo-quadrupolar geometry of A-( $\pi-\mathrm{D})_{2}$ type while $\mathbf{C 3}$ has geometry of the type A- $(\pi-\mathrm{D})_{3}$. The synthesis of these compounds has been described previously. ${ }^{63,64}$

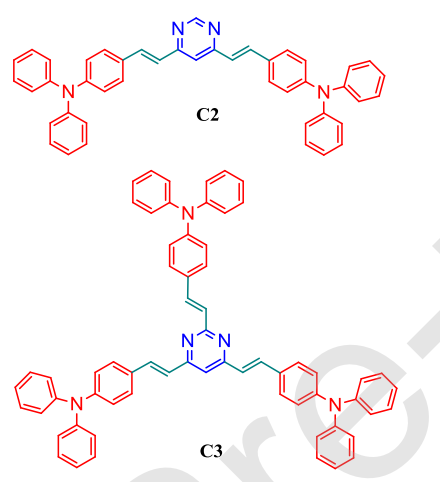

Figure 1. Chemical structures of the herein studied pyrimidine molecules.

\subsection{Steady state spectroscopy}

A Jasco V-650 UV-Vis and a Horiba Fluoromax spectrophotometer have been used for the detection of the absorption and fluorescence spectra of the samples in solutions respectively.

\subsection{Time resolved spectroscopy}

The excited state dynamics has been studied in $\mathrm{CHCl}_{3}$ solutions of the pyrimidines, with or without protonation, in the fs-ps and ns timescale. Initially, a femtosecond time resolved upconversion (FU) system, described in details in the past has been used. ${ }^{65,66}$ The FU system is based on a Ti:Sapphire femtosecond laser ( $80 \mathrm{fs}$ pulse duration, $80 \mathrm{MHz}$ repetition frequency, 800 $\mathrm{nm}$ ) which, after passing through a Second Harmonic Generator (SHG) crystal, is frequency doubled at $400 \mathrm{~nm}$ and is used for the excitation of the samples. The excitation power was below 
$2 \mathrm{~mW}$ while the samples were continuously rotating to avoid thermal effects. The Instrument's Response Function (IRF) was $\sim 250$ fs.

The ns dynamics have been detected via a Time Correlated Single Photon Counting (TCSPC) technique, based on a Fluotime 200 spectrometer (Picoquant). ${ }^{67}$ The samples were excited by a ps diode laser emitting $60 \mathrm{ps}$ pulses at $400 \mathrm{~nm}$. The system's IRF was $\sim 80 \mathrm{ps.} \mathrm{The} \mathrm{optical} \mathrm{density} \mathrm{of}$ the samples was $\sim 0.1$ at the excitation wavelength. Fitting of the ns dynamics has been made by a single or bi-exponential function after taking into account the systems' IRF. The quality of the fitting was judged by reducing the $\chi^{2}$ parameter and by visually inspecting the residuals. The excitation wavelength used at both techniques, as will be shown below, lays at the absorption band of the neutral molecules.

\section{Results and discussion}

\subsection{Steady State spectroscopy}

The absorption spectra of $\mathbf{C 2}$ in $\mathrm{CHCl}_{3}\left(10^{-5} \mathrm{M}\right)$ upon titration with $\mathrm{CSA}\left(\mathrm{pK}_{\mathrm{a}}=1.2\right), \mathrm{TFA}\left(\mathrm{pK}_{\mathrm{a}}=\right.$ $0.3)$ and $\mathrm{AcOH}\left(\mathrm{pK}_{\mathrm{a}}=4.8\right)$ are shown in figure 2. As shown before, the protonation occurs on one of the nitrogen atoms of the pyrimidine ring which plays the role as a monobasic compound $\left(\mathrm{pK}_{\mathrm{a}}\right.$ 1.1)..$^{23,56,63,64}$ After protonation of the first nitrogen atom, the basicity of the second one is decreased. This is because of the attractive inductive effect of the resulting quaternary nitrogen ( $\mathrm{pK}_{\mathrm{a}}$ for the second nitrogen 6.3).
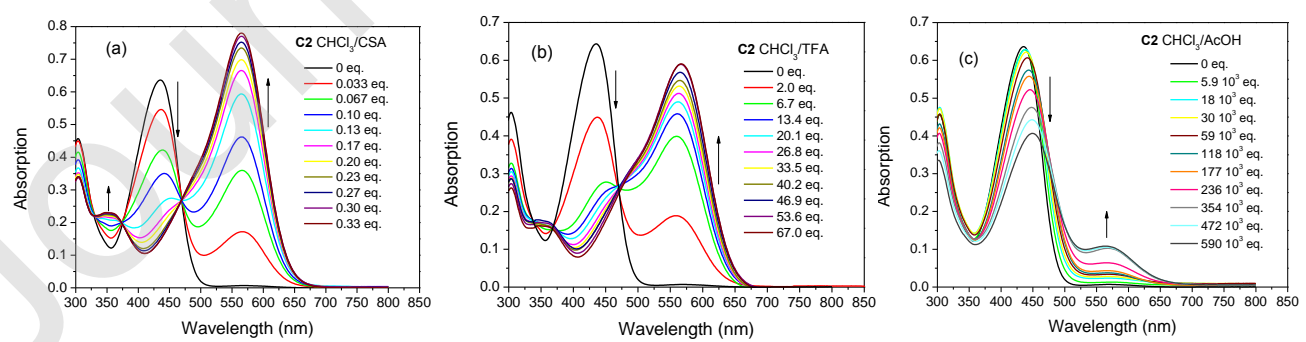

Figure 2. Absorption spectra of $\mathbf{C 2}$ in $\mathrm{CHCl}_{3}\left(10^{-5} \mathrm{M}\right)$ after addition of (a) CSA, (b) TFA and (c) $\mathrm{AcOH}$.

C2 in $\mathrm{CHCl}_{3}$ exhibits two absorption peaks at $436 \mathrm{~nm}$ and $~ 300 \mathrm{~nm}$. Titration with CSA decreases the intensity of these absorption bands while a new red-shifted band emerges with a 
peak at $566 \mathrm{~nm}$ attributed to the protonated species (Figure 2a). ${ }^{23}$ In addition, a second lowintensity absorption band at $350 \mathrm{~nm}$ appears. Two isosbestic points at 370 and $470 \mathrm{~nm}$ exist, clearly pointing to the existence of two distinct species i.e. the neutral and the acid generated protonated molecules. The absorption spectra upon addition of TFA, resemble those with CSA, with clear isosbestic points at 370 and $470 \mathrm{~nm}$ (Figure 2b). However, due to the important difference of $\mathrm{pK}_{\mathrm{a}}$ between pyrimidine and $\mathrm{AcOH}$, a large amount of this acid is necessary to protonate the pyrimidine ring. The behavior upon titration with $\mathrm{AcOH}$ is therefore slightly different (Figure 2c). First, the low intensity band at $350 \mathrm{~nm}$ is not obvious. Second, a new redshifted absorption band appears at $560 \mathrm{~nm}$, but its intensity is small and as a consequence no clear isosbestic point exists.

The corresponding spectra for $\mathbf{C 3}$ are shown in figure S1 where it is obvious that the behavior is similar to that of $\mathbf{C 2}$, but the changes are more pronounced. In $\mathrm{CHCl}_{3}, \mathbf{C} 3$ exhibits an absorption peak at $414 \mathrm{~nm}$, while after addition of only 0.067 eq. of CSA, this absorption band becomes negligible and the new red-shifted band, due to the protonated species, dominates the absorption. The above also apply for TFA. After addition of $\mathrm{AcOH}$, the changes are again more significant compared to C2. The new absorption band at $530 \mathrm{~nm}$, although not as intense as after adding CSA, is enhanced compared to $\mathbf{C 2}$.

Figure 3 presents the fluorescence spectra of $\mathbf{C 2}$, upon addition of acid, taken after excitation at the isosbestic point, in order to eliminate the changes in fluorescence due to the decrease in absorption intensity. Upon addition of CSA, the intensity of the main band at $540 \mathrm{~nm}$ decreases i.e. the fluorescence of the neutral species is quenched (Figure 3a). Gradually, a second bathochromically shifted band at $690-700 \mathrm{~nm}$ emerges due to the protonated molecules while an isoemissive point is obvious at $655 \mathrm{~nm}$. The intensity of the emission of protonated molecules seems to saturate after addition of 1.67 eq. The spectral behavior upon addition of TFA and AcOH is similar while in contrast to CSA, no isoemissive point exists and the red-shifted emission decreases upon adding high amounts of acid, probably due to an increase of polarity (Figures $3 \mathrm{~b}$ and 3c). Finally, figure 4 shows the 2D fluorescence maps of $\mathbf{C 2}$ in $\mathrm{CHCl}_{3}$ with 1 eq. $\mathrm{CSA}, 71 \cdot 10^{3}$ eq. of $\mathrm{AcOH}$ and 6.7 eq. of TFA respectively. The 2D maps show that upon excitation at 
approximately $440 \mathrm{~nm}$, both emission bands are revealed covering almost the whole visible spectrum. For excitation at longer wavelengths, the single emission of the protonated species is only observed, which, for the case of CSA, is more intense than that of the neutral species. For the case of $\mathrm{AcOH}$, the emission of the protonated species is not observed upon excitation at wavelengths longer than $500 \mathrm{~nm}$. This is due to its very low intensity compared to the fluorescence of the neutral species. If the excitation wavelength is scanned from $460 \mathrm{~nm}$ to 600 $\mathrm{nm}$ and after increasing the slits of the spectrometer, the low intensity fluorescence band of the protonated species is revealed (figure $\mathrm{S} 2$ ).
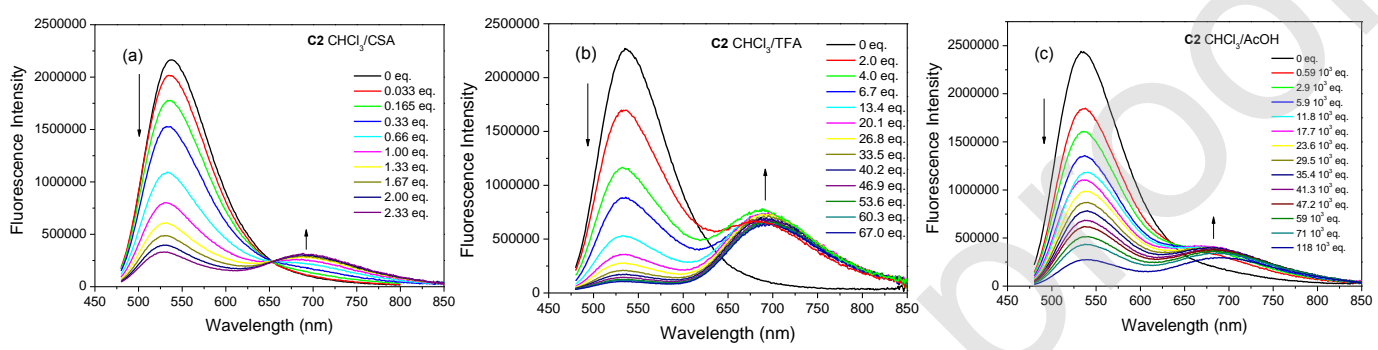

Figure 3. Fluorescence spectra of $\mathbf{C 2}$ in $\mathrm{CHCl}_{3}\left(10^{-5} \mathrm{M}\right)$ after addition of (a) CSA, (b) TFA and (c) $\mathrm{AcOH}$. Excitation at $470 \mathrm{~nm}$ (isosbestic point of the absorption spectra).
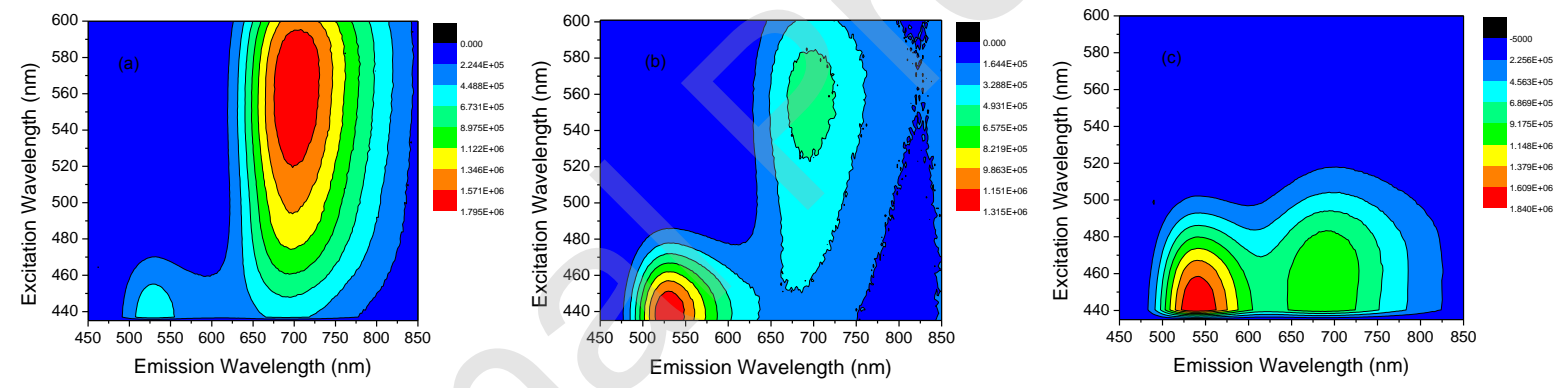

Figure 4. 2D fluorescence maps for $\mathbf{C 2}$ in $\mathrm{CHCl}_{3}\left(10^{-5} \mathrm{M}\right)$ with (a) 1 eq. CSA, (b) 6.7 eq. TFA and (c) $71 \cdot 10^{3}$ eq. AcOH.

Figure S3 displays the fluorescence spectra of $\mathbf{C 3}$ upon protonation with CSA, TFA and AcOH while figure S4 presents the 2D spectra. The main conclusion is that, clearly, the fluorescence intensity of the protonated species for $\mathbf{C 3}$ is much lower than for $\mathbf{C 2}$.

\subsection{Time resolved spectroscopy}

Next, in order to shed more light in the interaction of the acid with the solute molecules, the fluorescence dynamics has been studied by means of the FU method. Note that for these 
experiments, excitation was made at $400 \mathrm{~nm}$ and not at the isosbestic point. This is, however, not important since in time resolved experiments we are only interested in the change of dynamics and not in the absolute intensity of the fluorescence. Figure 5 shows the early dynamics of the neutral species i.e. detected at the main fluorescence band. It is observed that CSA does not change the initial dynamics (figures $5 \mathrm{a}$ and $5 \mathrm{~b}$ ) for both molecules. Similar results are obtained for TFA (figure $5 \mathrm{c}$ and $5 \mathrm{~d}$ ). On the other hand, the addition of $\mathrm{AcOH}$ results in a rapid decay, which mainly takes place within the first $20 \mathrm{ps}$ after excitation (figures $5 \mathrm{e}$ and $5 \mathrm{f}$ ). These results clearly constitute the first indication that $\mathrm{AcOH}$ interacts differently with the solutes compared to CSA and TFA. However, due to the short temporal range of the FU measurements, the effect of the acids on the excited state lifetime cannot be determined. Therefore, the dynamics were also detected in the ns timescale.

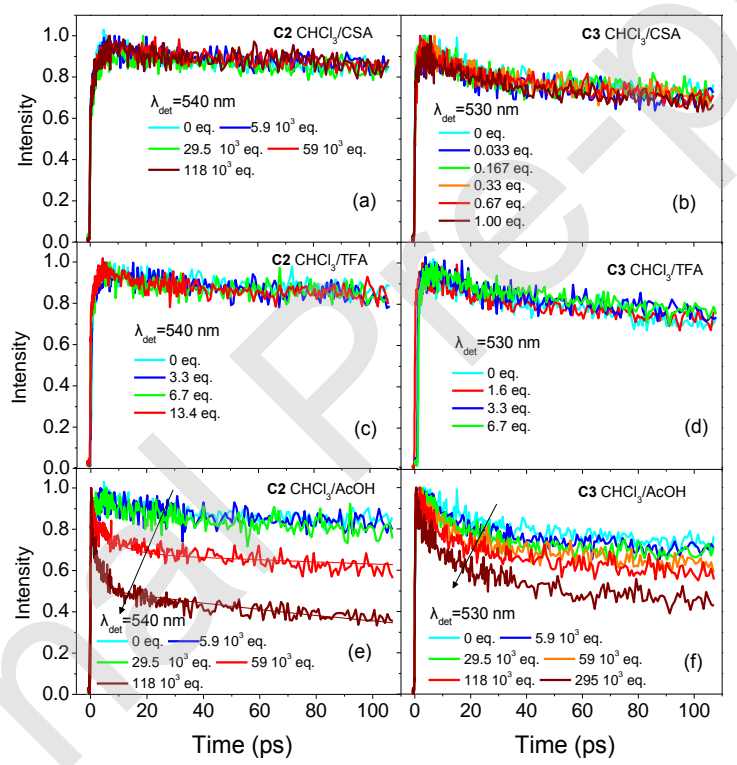

Figure 5. FU dynamics of $\mathbf{C 2}$ and $\mathbf{C 3}$ in $\mathrm{CHCl}_{3}$ detected at the peak of the neutral emission band, upon addition of various amounts of CSA (a) and (b), of TFA (c) and (d) and of AcOH (e) and (f). Note that the FU dynamics become faster upon addition of $\mathrm{AcOH}$ while they remain unchanged upon addition of CSA and TFA. The excitation wavelength was $400 \mathrm{~nm}$.

The ns decays have been measured for both the neutral and the protonated species i.e. at the 520540 and 670-700 nm bands. Figures 6 and 7 show the results for C2 upon addition of CSA and AcOH respectively while Figure S5 shows the results for C2 with TFA. More specifically, in figure 6a, it is observed that the decays of the neutral species at $540 \mathrm{~nm}$ do not change with the addition of acid. Fitting of these decays, resulted in a single exponential process with a lifetime of 
2.3 ns (Table 1) which is attributed, therefore, to the lifetime of the neutral $\mathbf{C 2}$ molecules in $\mathrm{CHCl}_{3}$. The fact that the lifetime does not change upon addition of CSA means that interactions of the neutral $\mathbf{C 2}$ molecules with the acid molecules in the excited state are excluded.

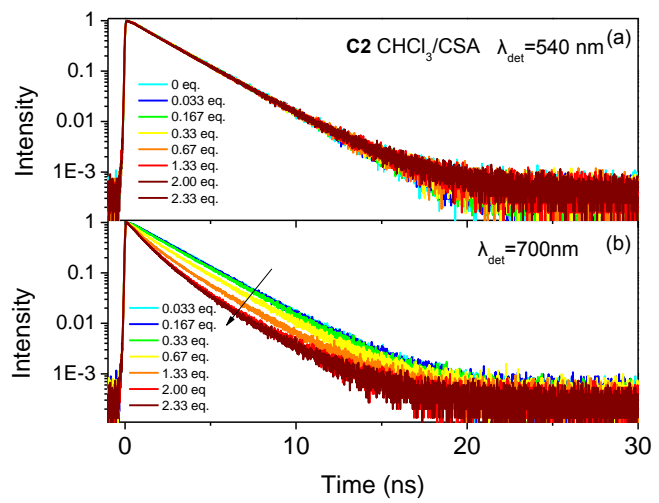

Figure 6. Fluorescence dynamics in the ns timescale for $\mathbf{C 2}$ in $\mathrm{CHCl}_{3}$ with different amounts of CSA detected at (a) $540 \mathrm{~nm}$ (main fluorescence band) and (b) $700 \mathrm{~nm}$ (fluorescence band of the protonated species). Note that the lifetime of the neutral species is not changed upon addition of CSA. The excitation wavelength was $400 \mathrm{~nm}$.

\begin{tabular}{ccccccc}
\hline $\begin{array}{c}\text { Detection } \\
\text { wavelength }\end{array}$ & Acid (eq.) & $\mathrm{A}_{1}$ & $\tau_{1}(\mathrm{~ns})$ & $\mathrm{A}_{2}$ & $\tau_{2}(\mathrm{~ns})$ & $\tau_{\text {avg }}(\mathrm{ns})$ \\
\hline $540 \mathrm{~nm}$ & 0 & & & 1 & 2.29 & 2.29 \\
& 0.033 & & & 1 & 2.3 & 2.3 \\
& 0.167 & & & 1 & 2.29 & 2.29 \\
& 0.33 & & & 1 & 2.29 & 2.29 \\
& 0.67 & & & 1 & 2.29 & 2.29 \\
& 1.33 & & & 1 & 2.3 & 2.3 \\
& 2.00 & & & 1 & 2.3 & 2.3 \\
$700 \mathrm{~nm}$ & 2.33 & & & 1 & 2.3 & 2.3 \\
& 0.033 & & & 1 & 2.34 & 2.34 \\
& 0.167 & & & 1 & 2.32 & 2.32 \\
& 0.33 & & & 1 & 2.29 & 2.29 \\
& 0.67 & 0.35 & 0.97 & 0.65 & 2.35 & 1.87 \\
& 1.33 & 0.57 & 0.89 & 0.43 & 2.27 & 1.48 \\
& 2.00 & 0.72 & 0.89 & 0.28 & 2.21 & 1.27 \\
& 2.33 & 0.74 & 0.9 & 0.26 & 2.19 & 1.23 \\
\hline
\end{tabular}

Table 1. Parameters of the nanosecond fluorescence dynamics for $\mathbf{C 2}$ in $\mathrm{CHCl}_{3}$ with different amounts of CSA detected at $540 \mathrm{~nm}$ (main fluorescence band) and $700 \mathrm{~nm}$ (fluorescence band of the protonated species). The excitation wavelength was $400 \mathrm{~nm}$.

Besides, the decays at $700 \mathrm{~nm}$ i.e. where the protonated species emit, are single exponential for small amounts of acid, with a lifetime of $\sim 2.3 \mathrm{~ns}$, meaning that the neutral and protonated species 
have the same lifetime. Note that excitation is made at $400 \mathrm{~nm}$ and thus, the neutral molecules are mainly excited in the time resolved experiments. Therefore, the fluorescence from the protonated species originates by an energy transfer mechanism. ${ }^{62}$ However, the decays become faster for CSA addition above 0.67 eq. (figure 6b), becoming bi-exponential with a short lifetime of $0.9 \mathrm{~ns}$, whose amplitude increases by increasing the quantity of acid and a second component of 2.2-2.3 ns which is similar to the lifetime of the protonated species (Table 1). The short component of $0.9 \mathrm{~ns}$ can be considered therefore as a quenching mechanism and can be ascribed to the stronger electron accepting ability of the protonated pyrimidine groups leading to enhanced ICT. According to the energy gap law, the excited state potential of the protonated low energy species with strong ICT, experiences conical intersections with the ground state energy potential leading to the decrease of lifetime and fluorescence quenching. This decrease of the average lifetime of the protonated species can be also correlated with the saturation of the fluorescence intensity upon increasing the amount of acid.

Clearly, the behavior is different upon addition of $\mathrm{AcOH}$ (figure 7). The decays of the neutral species at $540 \mathrm{~nm}$ become significantly faster upon addition of AcOH pointing to an interaction among neutral $\mathbf{C 2}$ molecules and $\mathrm{AcOH}$ in the excited state. The lifetime decreases from $2.29 \mathrm{~ns}$ for 0 eq. to $0.89 \mathrm{~ns}$ for $11810^{3}$ eq. of $\mathrm{AcOH}$ acid (Table 2). Besides, the decays at $700 \mathrm{~nm}$ of the protonated species exhibit a similar behavior with the neutral ones, becoming faster with addition of $\mathrm{AcOH}$. Figure $\mathrm{S} 5$ shows the ns decays for $\mathbf{C 2}$ after addition of $59 \cdot 10^{3}$ eq. of $\mathrm{AcOH}$ at various wavelengths across the neutral and protonated emission bands. The decays were found similar at all emission wavelengths showing negligible dependence on the detection wavelength.

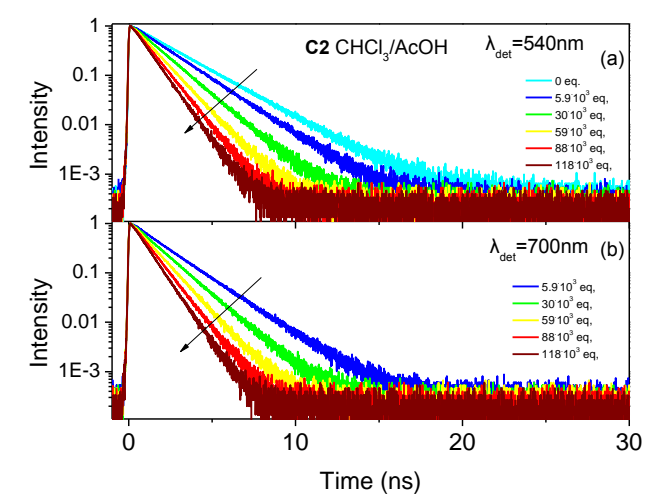


Figure 7. Fluorescence dynamics in the ns timescale for $\mathbf{C 2}$ in $\mathrm{CHCl}_{3}$ with different amounts of $\mathrm{AcOH}$ detected at (a) 540 (main fluorescence band) and (b) $700 \mathrm{~nm}$ (fluorescence band of the protonated species). Note that the lifetime of the neutral species decreases upon addition of $\mathrm{AcOH}$ which is in contrast to the case for CSA and TFA. The excitation wavelength was $400 \mathrm{~nm}$.

Finally, adding of TFA does not lead to a decrease of the lifetime of the neutral species which is again found 2.2-2.3 ns (Figure S6 and Table S1). However, when the amount of TFA exceeds 20.1 eq. a second decay mechanism with longer lifetime emerges. Its lifetime varies from 3.7 to $5.3 \mathrm{~ns}$ and its amplitude is less than $7 \%$.

\begin{tabular}{ccccc}
\hline $\begin{array}{c}\text { Detection } \\
\text { wavelength }\end{array}$ & Acid (eq.) & $\mathrm{A}_{1}$ & $\tau_{1}(\mathrm{~ns})$ & $\tau_{\text {avg }}(\mathrm{ns})$ \\
\hline $540 \mathrm{~nm}$ & 0 & 1 & 2.29 & 2.29 \\
& $5.9 \cdot 10^{3}$ & 1 & 1.93 & 1.93 \\
& $30 \cdot 10^{3}$ & 1 & 1.45 & 1.45 \\
& $59 \cdot 10^{3}$ & 1 & 1.19 & 1.19 \\
$700 \mathrm{~nm}$ & $88 \cdot 10^{3}$ & 1 & 1.01 & 1.01 \\
& $118 \cdot 10^{3}$ & 1 & 0.89 & 0.89 \\
& $5.9 \cdot 10^{3}$ & 1 & 1.87 & 1.87 \\
& $30 \cdot 10^{3}$ & 1 & 1.45 & 1.45 \\
& $59 \cdot 10^{3}$ & 1 & 1.19 & 1.19 \\
& $88 \cdot 10^{3}$ & 1 & 0.98 & 0.98 \\
& $118 \cdot 10^{3}$ & 1 & 0.86 & 0.86 \\
\hline
\end{tabular}

Table 2. Parameters of the nanosecond fluorescence dynamics for $\mathbf{C 2}$ in $\mathrm{CHCl}_{3}$ with different amounts of $\mathrm{AcOH}$ detected at 540 (main fluorescence band) and $700 \mathrm{~nm}$ (fluorescence band of the protonated species). The excitation wavelength was $400 \mathrm{~nm}$.

Based on the above findings and especially on the excited state dynamics, it is concluded that CSA and TFA acids quench the fluorescence of the neutral C2 molecules via a different mechanism than $\mathrm{AcOH}$. In the case of CSA and TFA, where the lifetime is not changed, the quenching is static while in the case of $\mathrm{AcOH}$ where the lifetime decreases, a dynamic quenching takes place ${ }^{68}$ However, in the latter case, static quenching also plays a role as will be discussed in the following.

In order to more quantitatively study the dynamic quenching of $\mathrm{C} 2$ upon addition of $\mathrm{AcOH}$, the Birks model ${ }^{69,} 70$ is applied. The corresponding kinetic scheme is shown in Figure S7. According to this, the neutral molecules decay towards the ground state by a rate constant $k_{N}$ and towards the protonated species by $k_{N P}$. Thus, the total decay rate constant of the neutral molecules is given by

$$
X=k_{N}+k_{N P}
$$


The corresponding rate constants for the protonated molecules are $k_{P}$ and $k_{P N}$ respectively. The fluorescence intensity decays of the neutral and protonated molecules are given by:

$$
\begin{gathered}
I_{N}(t)=A_{1 N} \exp \left(-\lambda_{1 N} t\right)+A_{2 N} \exp \left(-\lambda_{2 N} t\right) \\
I_{P}(t)=-A_{1 P} \exp \left(-\lambda_{1 P} t\right)+A_{2 P} \exp \left(-\lambda_{2 P} t\right)
\end{gathered}
$$

The parameters $A_{1 N}, A_{2 N}, \lambda_{1 N}$ and $\lambda_{2 N}$ are obtained by fitting the FU (Figure 5e) and ns dynamics (Figure 7a) of the neutral molecules respectively and are shown in Table 3. Upon fitting the FU results, the long lifetime obtained by the ns decays was used as a constant parameter. On the other hand, the rise part of $I_{P}(t)$ (first component of equation 3) cannot be determined since it was not possible to obtain FU measurements at the protonated emission band. Therefore the model will be only applied for the neutral species leading to the calculation of the rate coefficient for the formation of the protonated ones $k_{N P}$. The decay parameter $X$ is experimentally determined and defined as: ${ }^{69,70}$

$$
X=\frac{\left(A_{1 N} / A_{2 N}\right) \cdot \lambda_{1}+\lambda_{2}}{A_{1 N} / A_{2 N}+1}
$$

and the calculated results are also presented in Table 3. Finally, the $k_{N P}$ is found following equation 1 where $k_{N}$ is calculated by the decay of $\mathbf{C} 2$ without acid.

\begin{tabular}{cccccccc}
\hline Acid (eq.) & $A_{1 N}$ & $\lambda_{1 N}\left(10^{12} \mathrm{~s}^{-1}\right)$ & $A_{2 N}$ & $\lambda_{2 N}\left(10^{9} \mathrm{~s}^{-1}\right)$ & $X\left(10^{9} \mathrm{~s}^{-1}\right)$ & $k_{N}\left(10^{9} \mathrm{~s}^{-1}\right)$ & $k_{N P}\left(10^{9} \mathrm{~s}^{-1}\right)$ \\
\hline $59 \cdot 10^{3}$ & 0.24 & 0.14 & 0.76 & 0.84 & 34.6 & 0.44 & 34.16 \\
$118 \cdot 10^{3}$ & 0.50 & 0.26 & 0.50 & 1.12 & 130 & 0.44 & 129.56 \\
\hline
\end{tabular}

Table 3. Kinetic parameters for $\mathrm{C} 2$ upon addition of $\mathrm{AcOH}$, following the Birks model.

The Stern-Volmer plots ${ }^{68}$ for $\mathbf{C} 2$ upon addition of CSA, TFA and AcOH are given in figure 8.
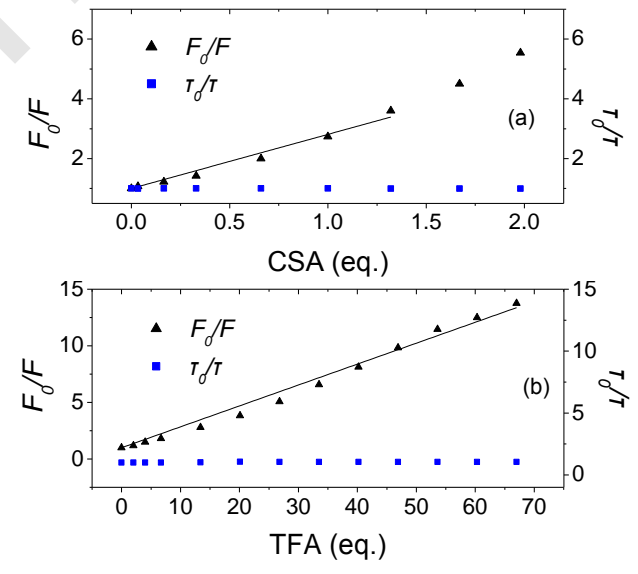


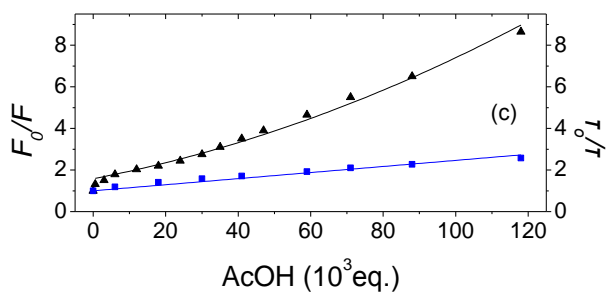

Figure 8. Stern Volmer plots for $\mathbf{C 2}$ in $\mathrm{CHCl}_{3}$ upon addition of (a) CSA, (b) TFA and (c) AcOH. $F$ and $F_{0}$ are the fluorescence intensities at the peak of the spectra after and before addition of acid. Similarly, $\tau$ and $\tau_{0}$ are the fluorescence lifetimes after and before addition of acid.

Fitting the intensity Stern-Volmer plots in Figures 8a and 8b, with the well-known equation $\frac{F_{0}}{F}=$ $1+K_{S}[Q]$, where $K_{S}$ is the association constant for static quenching and $[Q]$ the concentration of the quencher (here in eq.) we obtained $K_{S}=1.8$ eq. ${ }^{-1}$ for CSA and $K_{S}=0.18$ eq. ${ }^{-1}$ for TFA meaning that $50 \%$ of the fluorescence intensity is quenched when the acid concentration is 0.55 eq. for CSA and 5.55 eq. for TFA. However, in the case of CSA, the intensity quenching plot seems to deviate from linearity, possibly indicating higher order static quenching effects (for this reason the plot was fitted for acid concentration up to 1.3 eq.). The quenching process upon adding $\mathrm{AcOH}$ has a more complicated feature. The reduction of the fluorescence lifetime indicates the existence of a dynamic (diffusional) mechanism. However, the plots of $\frac{F_{0}}{F}$ and $\frac{\tau_{0}}{\tau}$ do not have the same slope as expected for a purely dynamic quenching. More specifically, the intensity quenching plot $\left(\frac{F_{0}}{F}\right.$ vs. acid) has a higher slope than the lifetime quenching one ( $\frac{\tau_{0}}{\tau}$ vs. acid) and a slight nonlinear behavior (upward curvature). Therefore, the quenching process upon adding $\mathrm{AcOH}$ is a combination of both static (complex association) and dynamic (diffusional) mechanisms. Therefore, the fitting of the intensity quenching curve is made with the equation $\frac{F_{0}}{F}=$ $\left(1+K_{D}[Q]\right)\left(1+K_{s}[Q]\right)$ where $K_{D}$ is the dynamic quenching constant and $\frac{\tau_{0}}{\tau}=\left(1+K_{D}[Q]\right) .{ }^{68}$ Fitting initially the lifetime quenching curve in Figure $8 \mathrm{c}$, we obtain $K_{D}=0.011 \cdot 10^{-3}$ eq. ${ }^{-1}$. Then $K_{S}$ can be easily found by the intensity quenching curve to be $K_{S}=0.022 \cdot 10^{-3}$ eq. $^{-1}$.

C3 exhibits a similar behavior regarding the dynamics i.e. the lifetime of the neutral species is unchanged upon adding CSA and TFA, while it decreases upon adding $\mathrm{AcOH}$. The corresponding results are presented in figures S8-S11 and Tables S2, S3 and S4. Specifically, the decays of the neutral species display a $\sim 2.30 \mathrm{~ns}$ component which is considered as the lifetime of the $\mathbf{C 3}$ 
molecules (Figure S8 and Table S2). However, in the case of CSA, although the average lifetime remains the same, the decays become bi-exponential, when the quantity of CSA exceeds 1.33 eq., with a $2.10 \mathrm{~ns}$ and a $2.5-4.5 \mathrm{~ns}$ components. The fact that the neutral lifetime remains almost unchanged when CSA is added, points to a static quenching as in the case of C2. Similarly to CSA, when adding TFA, the lifetime of the neutral species again remains unchanged, while a slower component also emerges at high amounts of acid (Figure S9 and Table S3). On the other hand, upon addition of $\mathrm{AcOH}$, the excited state lifetime of the neutral molecules decreases from 2.32 to $0.86 \mathrm{~ns}$ (Figure S10 and Table S4), meaning that a dynamic quenching is operative as was also confirmed for C2. Finally, the decays of the protonated species, detected at $670 \mathrm{~nm}$, also become accelerated with increasing the amount of acids. This is due to the enhanced ICT behavior of the protonated pyrimidines.

\section{Conclusions}

In conclusion, the photophysics of two pyrimidine chromophores, bearing the A- $(\pi-\mathrm{D})_{2}$ and $\mathrm{A}-(\pi-$ D) 3 structure, have been studied focusing on their excited state dynamics, upon protonation with three common acids i.e. $\mathrm{CSA}, \mathrm{AcOH}$ and TFA in order to shed light on the interactions of solute and acid molecules. A quenching of the fluorescence of the neutral chromophores after addition of acid is revealed by steady state spectroscopy, while the generation of a red-shifted emission band, originating from the protonated species, is also observed. Upon addition of CSA and TFA, the excited state dynamics of the chromophores are not changed. This strongly shows that the interaction among the solute and acid molecules is operative in the ground state and the quenching is considered as static. On the other hand, the excited state dynamics of the neutral molecules becomes faster upon interaction with the $\mathrm{AcOH}$ molecules. This observation together with steady state measurements and the Stern-Volmer plots indicate that the interaction leading to the quenching, takes place both in the excited and ground state namely, the quenching has a dynamic and a static nature. 


\section{Author Statements}

Author

Role

Fotis Kournoutas

Experiments

Ioannis Konstantinos Kalis

Experiments

Michaela Fecková

Experiments, Synthesis

Sylvain Achelle

Synthesis, Supervision

Mihalis Fakis

Supervision, Writing - review \& editing

\section{Declaration of interests}

The authors declare that they have no known competing financial interests or personal relationships that could have appeared to influence the work reported in this paper.

\section{Acknowledgements}

M.F. thanks the Région Bretagne, France for funding of her Ph D.

\section{References}

1. H. F. Higginbotham, R. P. Cox, S. Sandanayake, B. A. Graystone, S. J. Langford, T. D. M. Bell, A fluorescent " 2 in 1" proton sensor and polarity probe based on coresubstituted naphthalene diimide, Chem. Commun. 49 (2013) 5061-5063.

2. G. Signore, R. Nifosì, L. Albertazzi, R. Bizzarri, A. Ranieri, Novel Coumarin Fluorescent Sensor to Probe Polarity Around Biomolecules, J. Biomed. Nanotechnology 5 (2009) 722729.H. Sunahara, Y. Urano, H. Kojima, T. Nagano, Design and Synthesis of a Library of BODIPY-Based Environmental Polarity Sensors Utilizing Photoinduced Electron-TransferControlled Fluorescence ON/OFF Switching, J. Am. Chem. Soc. 129 (2007) 5597-5604. 
4. A. K. Mora, S. Murudkar, A. Alamelu, S. Chattopadhyay, S. Nath, Role of solvent Hbonding and polarity on photophysical properties of a benzothiazole-based ratiometric amyloid fibril sensor, J. Photochem. and Photobiol. A: Chem. 373 (2019) 20-27.

5. S. F. Zhou, J. Shao, Y. Yang, J. Zhao, H. Guo, X. Li, S. Ji, Z. Zhang, Molecular Rotors as Fluorescent Viscosity Sensors: Molecular Design, Polarity Sensitivity, Dipole Moments Changes, Screening Solvents, and Deactivation Channel of the Excited States, Eur. J. Org. Chem. (2011) 4773-4787.

6. S. C. Lee, J. Heo, H. C. Woo, J. -A. Lee, Y. H. Seo, C. -L. Lee, S. Kim, O. -P. Kwon, Fluorescent Molecular Rotors for Viscosity Sensors, Chem. Eur. J. 24 (2018) 13706-13718.

7. S. C. Lee, J. Heo, J. -W. Ryu, C. -L. Lee, S. Kim, J. -S. Tae, B. -O. Rhee, S. -W. Kim, O. -P. Kwon, Pyrrolic molecular rotors acting as viscosity sensors with high fluorescence contrast, Chem. Commun. 52 (2016) 13695-13698.

8. S. Raut, J. Kimball, R. Fudala, H. Doan, B. Maliwal, N. Sabnis, A. Lacko, I. Gryczynski, S. V. Dzyubad, Z. Gryczynski, A homodimeric BODIPY rotor as a fluorescent viscosity sensor for membrane-mimicking and cellular environments, Phys. Chem. Chem. Phys. 16 (2014) 27037-27042.

9. J. Qiu, S. Jiang, H. Guo, F. Yang, An AIE and FRET-based BODIPY sensor with large Stoke shift: Novel $\mathrm{pH}$ probe exhibiting application in $\mathrm{CO}_{3}{ }^{2-}$ detection and living cell imaging, Dyes Pigm. 157 (2018) 351-358.

10. L. Chen, L. He, F. Ma, W. Liu, Y. Wang, M. A. Silver, L. Chen, L. Zhu, D. Gui, J. Diwu, Z. Chai, S. Wang, Covalent Organic Framework Functionalized with 8-Hydroxyquinoline as a Dual-Mode Fluorescent and Colorimetric pH Sensor, ACS Appl. Mater. Interfaces 10 (2018) 15364-15368.

11. M. Martineau, A. Somasundaram, J. B. Grimm, T. D. Gruber, D. Choquet, J. W. Taraska, L. D. Lavis, D. Perrais, Semisynthetic fluorescent $\mathrm{pH}$ sensors for imaging exocytosis and endocytosis, Nat. Commun. 8 (2017) 1412.

12. R. Gotor, P. Ashokkumar, M. Hecht, K. Keil, K. Rurack, Optical pH Sensor Covering the Range from $\mathrm{pH}$ 0-14 Compatible with Mobile-Device Readout and Based on a Set of Rationally Designed Indicator, Dyes. Anal. Chem. 89 (2017) 8437-8444.

13. M. Matsui, T. Yamamoto, K. Kakitani, S. Biradar, Y. Kubota, K. Funabiki, UV-vis absorption and fluorescence spectra, solvatochromism, and application to $\mathrm{pH}$ sensors of novel xanthene dyes having thienyl and thieno[3,2-b]thienyl rings as auxochrome, Dyes Pigm. 139 (2017) 533-540.

14. Z. Li, L. J. Li, T. Sun, L. Liu, Z. Xie, Benzimidazole-BODIPY as optical and fluorometric pH sensor, Dyes Pigm. 128 (2016) 165-169.

15. S. Achelle, J. Rodríguez-López, F. Bureš, F. Robin-le Guen, Dipicolylamine Styryldiazine Derivatives: Synthesis and Photophysical Studies, Dyes Pigm. 121 (2015) 305-311. 
16. C. Hadad, S. Achelle, I. López-Solera, J. C. García-Martínez, J. Rodríguez-López, Metal Cation Complexation Studies of 4-Arylvinyl-2,6-di(pyridin-2-yl)pyrimidines: Effect on the Optical Properties, Dyes Pigm. 97 (2013) 230-237.

17. M. Z. Wu, J. Y. Shi, P. Y. Chen, L. Tian, A three-dimensional Cd(II) metal-organic framework: a bifunctional luminescence sensor for benzaldehyde and $\mathrm{Fe}^{2+}$ ions, New J. Chem. 43 (2019) 10575-10582.

18. Z. Zhan, X. Liang, X. Zhang, Y. Jia, M. Hu, A water-stable europium-MOF as a multifunctional luminescent sensor for some trivalent metal ions $\left(\mathrm{Fe}^{3+}, \mathrm{Cr}^{3+}, \mathrm{Al}^{3+}\right), \mathrm{PO}_{4}{ }^{3-}$ ions, and nitroaromatic explosives, Dalton Trans. 48 (2019) 1786-1794.

19. Z. Guo, T. Hu, X. Wang, T. Sun, T. Li, Q. Niu, Highly sensitive and selective fluorescent sensor for visual detection of $\mathrm{Cu} 2+$ in water and food samples based on oligothiophene derivative $\mathrm{J}$. Photochem. Photobiol. A 371 (2019) 50-58.

20. M. Denis, J. Pancholi, K. Jobe, M. Watkinson, S. M. Goldup, Chelating Rotaxane Ligands as Fluorescent Sensors for Metal Ions, Angew. Chem. Int. Ed. 57 (2018) 5310-5314.

21. L. Yang, C. Lian, X. Li, Y. Han, L. Yang, T. Cai, C. Shao, Highly Selective Bifunctional Luminescent Sensor toward Nitrobenzene and $\mathrm{Cu}^{2+}$ Ion Based on Microporous Metal-Organic Frameworks: Synthesis, Structures, and Properties, ACS Appl. Mater. Interfaces 9 (2017) 1720817217.

22. W. Yan, C. Zhang, S. Chen, L. Han, H. Zheng, Two Lanthanide Metal-Organic Frameworks as Remarkably Selective and Sensitive Bifunctional Luminescence Sensor for Metal Ions and Small Organic Molecules, ACS Appl. Mater. Interfaces 9 (2017) 1629-1634.

23. S. Achelle, J. Rodríguez-López, F. Bureš, F. Robin-le Guen, Tuning the photophysical properties of push-pull azaheterocyclic chromophores by protonation: a brief overview of a French-SpanishCzech Project. Chem. Rec. doi: 10.1002/tcr.201900064

24. S. W. Kim, T. -M. Um, S. Shin S, Brønsted acid-catalyzed $\alpha$-halogenation of ynamides from halogenated solvents and pyridine-N-oxides, Chem. Commun. 53 (2017) 2733-2736.

25. M. Broquier, S. Soorkia, C. Dedonder-Lardeux, C. Jouvet, P. Theulé, G. Grégoire, Twisted Intramolecular Charge Transfer in Protonated Amino Pyridine, J. Phys. Chem. A 120 (2016) 3797-3809.

26. J. Xiong, K. Wang, Z. Yao, B. Zou, J. Xu, X.-H. Bu, Multi-Stimuli-Responsive Fluorescence Switching from a Pyridine-Functionalized Tetraphenylethene AIEgen, ACS Appl. Mater. Interfaces 10 (2018) 5819-5827.

27. Y. Wei, Q. Li, W. Li, J. Cheng, S. A. C. McDowell, Influence of the protonation of pyridine nitrogen on pnicogen bonding: competition and cooperativity. Phys. Chem. Chem. Phys. 18 (2016) 11348-11356.

28. E. Cariati, C. Botta, S. G. Danelli, A. Forni, A. Giaretta, U. Giovanella, E. Lucenti, D. Marinotto, S. Righetto, R. Ugo, Solid state and solution fine tuning of the linear and 
nonlinear optical properties of (2-pyrene-1-yl-vinyl)pyridine by protonation-deprotonation reactions, Chem. Commun. 50 (2014) 14225-14228.

29. M. Li, Y. Yuan, Y. Chen, Acid-Induced Multicolor Fluorescence of Pyridazine Derivative, ACS Appl. Mater. Interfaces 10 (2018) 1237-1243.

30. J. Do, Y. Kim, A. J. Attias, D. Kreher, E. Kim, Patterning of pH Sensitive Fluorescent Bipyridazine Derivatives, J. Nanosc. Nanotech. 10 (2010) 6874-6878.

31. E. V. Verbitskiy, E. M. Dinastiya, A. A. Baranova, K. O. Khokhlov, R. D. Chuvashov, Y. A. Yakovleva, N. I. Makarova, E. V. Vetrova, A. V. Metelitsa, P. A. Slepukhin, G. L. Rusinov, O. N. Chupakhin, V. N. Charushin, Dyes Pigm. 159 (2018) 35-44.

32. S. Kato, Y. Yamada, H. Hiyoshi, K. Umezu, Y. Nakamura, Series of carbazole-pyrimidine conjugates: syntheses and electronic, photophysical, and electrochemical properties, J. Org. Chem. 80 (2015) 9076-9090.

33. H. Muraoka, T. Obara, S. Ogawa, Systematic synthesis, comparative studies of the optical properties, and the ICT-based sensor properties of a series of 2,4,6-tri(5-aryl-2thienyl)pyrimidines with the D- $\pi$-A system, Tetrahedron Lett. 57 (2016) 3011-3015.

34. R. W. Sinkeldam, P. Marcus, D. Uchenik, Y. Tor, Multisensing Emissive Pyrimidine, ChemPhysChem 12 (2011) 2260-2265.

35. L. Xu, H.Zhu, G. Long, J. Zhao, D. Li, R. Ganguly, Y. Li, Q. -H. Xu, Q. Zhang, 4Diphenylamino-phenyl substituted pyrazine: nonlinear optical switching by protonation, J. Mater. Chem. C. 3 (2015) 9191-9196.

36. H. Muraoka, N. Iwabuchi, A. Ogawa, A series of 2,5-bis(5-aryl-2-thienyl)pyrazines with a linearshaped (D-pi)(2)-A system: synthesis and study of the optical properties including fluorosolvatochromism and proton-base-sensing, Bull. Chem. Soc. Jpn. 92 (2019) 1358-1369.

37. V. Schmitt, S. Moschel, H. Detert, Diaryldistyrylpyrazines: Solvatochromic and Acidochromic Fluorophores, Eur. J. Org. Chem. (2013) 5655-5669.

38. C. W. Lee, J. K. Kim, S. H. Joo, J. Y. Lee, High Quantum Efficiency Blue Phosphorescent Organic Light-Emitting Diodes Using 6-Position-Modified Benzofuro[2,3-b]pyridine Derivatives, ACS Appl. Mater. Interfaces 56 (2013) 2169-2173.

39. W. Li, J. Li, D. Liu, V. Li, D. Zhang, Dual n-type units including pyridine and diphenylphosphine oxide: effective design strategy of host materials for high-performance organic light-emitting diodes, Chem. Sci. 7 (2016) 6706-6714.

40. J. Lee, S. Lee, J. H. Kim, S. O. Kang, W. S. Han, Triaryl boron derivatives of pyridine as electron transporting materials for blue phosphorescent organic light-emitting diodes, Org. Electron. 62 (2018) 5-11.

41. Y. Hu, M. Kye, J. Y. Young, Y. B. Lim, J. Yoon, Design for a small molecule based chemosensor containing boron and pyridine moieties to detect HF, Sens. Actuators B: Chem. 255 (2018) 2621-2627. 
42. S. Xu, Y. Zhu, R. Li, J. Su, S. Li, H. Zhou, J. Wu, Y. Tian, Thiophene-based pyridine derivatives: synthesis, crystal structures, two-photon absorption properties and bio-imaging applications in the near-IR region, New J. Chem. 40 (2016) 8809-8814.

43. C. K. R. Namboodiri, S. R. Bongu, P. B. Bisht, R. Mukkamala, B. Chandra, I. S. Aidhen, T. J. Kelly, J. T. Costello, Enhanced two photon absorption cross section and optical nonlinearity of a quasi-octupolar molecule, Journal of Photochemistry and Photobiology A: Chemistry 314 (2016) $60-65$.

44. S. Achelle, N. Plé, A. Turck, Incorporation of pyridazine rings in the structure of functionalized $\pi$-conjugated materials, RSC Adv. 1 (2018) 364-388.

45. S. Achelle, N. Plé, Pyrimidine ring as building block for the synthesis of functionalized $\pi$ conjugated materials, Curr. Org. Synth. 9 (2012) 163-187.

46. S. Achelle, C. Baudequin, N. Plé, Luminescent materials incorporating pyrazine or quinoxaline moieties, Dyes Pigm. 98 (2013) 575-600.

47. R. Komatsu, H. Sasabe, J. Kido, Recent progress of pyrimidine derivatives for high-performance organic light-emitting devices, J. Photonics Energy 8 (2018) 032108.

48. G. N. Lipunova, E. V. Nosova, V. N. Charushin, O. N. Chupakhin, Functionalized quinazolines and pyrimidines for optielectronic materials, Curr. Org. Synth. 15 (2018) 793-814.

49. E. V. Nosova, S. Achelle, G. N. Lipunova, V. N. Charuchin, O. N. Chupakhin, Functionalized benzazines as luminescent materials and components for optoelectronics, Russ. Chem. Rev. doi: 10.1070/RCR4887

50. D. Liu, Z. Zhang, H. Zhang, Y. Wang, A novel approach towards white photoluminescence and electroluminescence by controlled protonation of a blue fluorophore, Chem. Commun. 49 (2013) 10001-10003.

51. C. Romero-Nieto, S. Durben, I. M. Kormos, T. Baumgartner, Simple and Efficient Generation of White Light Emission From Organophosphorus Building Blocks, Adv. Funct. Mater. 19 (2009) 3625-3631.

52. M. Li, Y. Yuan, Y. Chen, Acid-induced Multicolor Fluorescence of Pyridazine Derivative, ACS Appl. Mater. Interfaces 101 (2018) 1237-1243.

53. J. Tydlitát, S. Achelle, J. Rodríguez-López, O. Pytela, T. Mikýsek, N. Cabon, F. Robin-le Guen, D. Miklík, Z. Růžičková, F. Bureš, Photophysical properties of acid-responsive triphenylamine derivatives bearing pyridine fragments: Towards white light emission, Dyes Pigm. 146 (2017) 467-478.

54. S. Achelle, J. Rodríguez-López, N. Cabon, F. Robin-le Guen, Protonable pyrimidine derivative for white light emission, RSC Adv. 5 (2015) 107396-107399. 
55. S. Achelle, J. Rodríguez-López, C. Katan, F. Robin-le Guen, Luminescence Behavior of Protonated Methoxy-Substituted Diazine Derivatives: Toward White Light Emission, J. Phys. Chem. C 120 (2016) 26986-26995.

56. S. Achelle, J. Rodríguez-López, M. Larbani, R. Plaza-Pedroche, F. Robin-le Guen, Carbazoleand triphenylamine-substituted pyrimidines: synthesis and photophysical properties, Molecules 24 (2019) 1742.

57. Z. -W. Wang, Q.-Y. Cao, S. Lin, L. Zhuo, Z.-H. Li 2,6-Diphenylpyridine-based fluorophores:Synthesis, photophysical properties and effects of protonation J. of Photochem. Photobiol. A: Chemistry 251 (2013) 106-112.

58. A. Michaleviciute, E. Gurskyte, D. Y. Volyniuk, V. V. Cherpak, G. Sini, P. Y. Stakhira, J. V. Grazulevicius, Star-Shaped Carbazole Derivatives for Bilayer White Organic Light- Emitting Diodes Combining Emission from Both Excitons and Exciplexes, J. Phys. Chem. C 116 (2012) 20769-20778.

59. S. Mukherjee, P. Thilagar, Organic White-Light Emitting Materials, Dyes Pigm. 110 (2014) $2-27$.

60. B. W. D’Andrade, R. J. Holmes, S. R. Forrest, Efficient Organic Electrophosphorescent White-Light-Emitting Device with a Triple Doped Emissive Layer, Adv. Mater. 16 (2004) 624-628.

61. Y. Sun, N. C. Giebink, H. Kanno, B. Ma, M. E. Thompson, S. R. Forrest, Management of Singlet and Triplet Excitons for Efficient White Organic Light-Emitting Devices, Nature 440 (2006) 908-912.

62. F. Kournoutas, K. Seintis, N. Karakostas, J. Tydlitát, S. Achelle, G. Pistolis, F. Bureš, M. Fakis, Photophysical and Protonation Time Resolved Studies of DonorAcceptor Branched Systems With Pyridine Acceptors, J. Phys. Chem. A 123 (2019) 417-428.

63. S. Achelle, I. Nouira, B. Pfaffinger, Y. Ramonden, N. Plé, J. Rodríguez-López, V-Shaped 4,6-Bis(arylvinyl)pyrimidine Oligomers: Synthesis and Optical Properties, J. Org. Chem. 74 (2009) 3711-3717.

64. M. Fecková, P. le Poul, F. Robin-le Guen, T. Roisnel, O. Pytela, M. Klikar, F. Bureš, S. Achelle, 2,4-distyryl and 2,4,6-tristyrylpyrimidines: synthesis and photophysical properties, J. Org. Chem. 83 (2018) 11712-11726.

65. A. Koutsoubelitis, K. Seintis, D. Tsikritzis, J. Oriou, C. Brochon, E. Cloutet, G. Hadziioannou, M. Vasilopoulou, S. Kennou, M. Fakis, L. C. Palilis, Photophysics, Electronic Structure and Solar Cell Performance of a Donor-Acceptor Poly(N-dodecyl-2,7-carbazolealt-benzothiadiazole), Org. Electron. 59 (2018) 202-212.

66. N. Karakostas, E. Martinou, A. Kaloudi-Chantzea, K. Seintis, H. Oberacher, F. Pitterl Florian, M. Fakis, J. Kallitsis, G. Pistolis, Energy Transfer within Self-Assembled Cyclic 
Multichromophoric Arrays Based on Orthogonally Arranged Donor - Acceptor Building Blocks, Faraday Disc. 185, (2015) 433-454.

67. N. Droseros, K. Seintis, M. Fakis, S. Gardelis, A. Nassiopoulou, Steady State and Time Resolved Photoluminescence Properties of $\mathrm{CuInS}_{2} / \mathrm{ZnS}$ Quantum Dots in Solutions and in Solid Films, J. Lumin. 167 (2015) 333-338.

68. J. R. Lacowicz. Principles of Fluorescence Spectroscopy, Springer, 2006.

69. J. B. Birks. Photophysics of Aromatic Molecules, Wiley, 1970.

70. T. Annable, I. Soutar, G. Rumbles, a,a-Dinaphthylpropane: a model for polymer photophysics and a probe for the investigation of macromolecular dynamics? Polymer 34 (1993) 3576-3581. 